\title{
Antibacterial Effect of Silver Nanoparticles Deposited on Polyamide Fabric Treated With Glow Discharge Plasma under Atmospheric Pressure (GDPAP)
}

\author{
H.M. Ahmed ${ }^{1}$, A.A. EL-Halwagy ${ }^{1}$, M.A. EL-Kashouty ${ }^{1}$, A. A. El- Aaty ${ }^{1}$ and A. \\ A Garamoon ${ }^{2}$ \\ ${ }^{1}$ Textile Research Division, National Research Centre, Dokki, ${ }^{2}$ Center of plasma \\ technology, Faculty of science, Al-Azhar university, Nasr city, Cairo, Egypt.
}

\begin{abstract}
T HIS WORK studies the possibility of using (GDPAP) to activate the polyamide fabric surface. This activation facilitates the loading of sliver nano particles NPs onto the polyamide fabric and as a result improves its bacterial properties. The washing durability on silver-loaded fabric for Gram-positive bacterium Staphylococcus aureus and Gram-negative bacterium Escherichia coli were estimated. Transimsion Electron Microscopy (TEM) observation of silver nanoparticles showed their shape, and size distribution. The deposition of nanosilver on polyamide fabric was characterized using atomic force microscope (AFM) and amount of silver in fabric was determined by X-ray fluorescence (XRF). The change induced in roughness, wettability, and printability of polyamide 6 fabric is given. The surface resistivity of polyamide is affected after plasma treatment.
\end{abstract}

Keywords: Antibacterial; Silver Nanoparticles; Polyamide Fabric; Discharge Plasma.

\section{Introduction}

According to the environmental regulations and due to the importance of improved human life a new area has developed in the realm of textile finishing. The control of microorganisms on textile fabrics extends into diverse areas as the hospital environment and every-day household. It is well- known that all textiles are made of natural fibers or synthetic ones that both have no resistance to bacteria or pathogenic fungi ${ }^{(1)}$.

Surrounded by all surface modification techniques, plasma was suggested as a good method to modify surface properties where it is a non-aqueous and biologically friendly processing method, which does not include large amount of water and chemicals. Hence, low temperature plasma technology has been investigated for the surface modification of textiles such as improving wettability, (2) water repellency ${ }^{(3)}$, soil release ${ }^{(3)}$, dyeing (4) and printing properties, ${ }^{(5)}$ as well as depositing functional films on material surfaces ${ }^{(6)}$.

Ablation and deposition can be achieve by using Plasma technology, which are considered dry and eco-friendly, processes ${ }^{(7)}$. Ablation permits a wide-ranging cleaning of textiles from industrial residuals and deposition can be skillful in the nanometer variety to achieve new functionalities while, the textile properties keep on unaffected with both treatments. Plasma technology is achievement popularity in the fabric production due to its numerous advantages ended conventional wet processing methods, where it is avoiding remaining fabrication as found in wet chemical procedures. Still, for the removal from production, both the probability of scale-up and economic facets are required to observe ${ }^{(7)}$.

Although the field of medical devices has made insignificant technological development, the bacterial establishment of biomaterials residues a main medical problem, often leading to device disaster and can be deadly ${ }^{(8)}$. Some of the other effective anti-bacterial procedures- presently under examination- is depend on the enterprise of a coating that encloses silver ${ }^{(9-12)}$. The toxic special effects of metallic and nano silver are bacterial- 
specific and interaction will prove incurable to pathogens inclosing sulfhydryl functional groups (11). It has been confirmed that, silver is operative in killing over 650 disease-causing organisms, and is energetic against gram-negative bacteria, such as Pseudomonas aeruginosa, as well as gram-positive bacteria, fungi, protozoa and certain viruses.

This work aimed to:

- The probability of using the plasma technique for fiber surface activation to enable the loading of silver nanoparticles from a colloid onto the polyamide fabrics and hence increased their antibacterial properties.

- The laundering durability of the succeeded bactericidal effects on gram-positive bacterium staphylococcus and gram-negative bacterium Escherichia coli.

\section{Experimental}

\section{Material}

Fabric

Polyamide 6 knitted fabric 210 denier/35 filament yarns of chemical structure $\mathrm{NH}_{2}\left[\left(\mathrm{CH}_{2}\right)_{5}-\mathrm{CONH}\right]$

$\mathrm{COOH}$, and density $1.14 \mathrm{~g} / \mathrm{cm}^{3}$ was supplied by El-Nasr Spinning Weaving and Knitting Company (Shourbagy, Cairo, Egypt). The fabric was soaped at $60^{\circ} \mathrm{C}$ for 30 minutes, thoroughly washed, and air dried at room temperature.

\section{Chemical}

Silver nano-particals of size $<100 \mathrm{~nm}$ were supplied from Aldrich-German Co.. Other chemicals such as urea, formic acid (85\%), ammonium sulphat (1:2) are of laboratory grad.

\section{Thickener and Dyestuff}

Myprogum is used as thickening agent and commercial acid dye C.I. acid blue ( Supralan
-225) of the following chemical structure - was used and supplied by Dystar Co.

\section{Methods}

\section{Fabric Treatments}

Polyamide fabrics were padded in nano silver solution and squeezed to $100 \%$ pick up. Then, the wetted fabrics with sliver solution were placed between two electrodes and exposed to glow discharge plasma under atmospheric pressure at discharge power 0.5 and $1 \mathrm{~mA}$ for different intervals of exposure time $0.5,1,2,5$ minutes.

\section{Plasma Set up}

The experimental setup (Figure 1) consists of two copper plane-parallel electrodes of 2.5 $\mathrm{cm}$ diameter. The two electrodes were covered with two porous alumina $\mathrm{Al}_{2} \mathrm{O}_{3}$ sheets of $3.5 \mathrm{~mm}$ thickness and $4 \mathrm{~cm}$ diameter. The distance between the two dielectric plates was $1.1 \mathrm{~mm}$. A high voltage transformer $(1-10 \mathrm{kV})$, which generates sinusoidal voltage with a frequency of $50 \mathrm{~Hz}$, was used as an electric power supply to derive the discharge system. The discharge was operated in open air under atmospheric pressure. The applied potential $\left(V_{\mathrm{a}}\right)$ across the electrodes and the current (I ) passing through the system were recorded using a digital oscilloscope (HAMEG HM407-40 $\mathrm{MHz})$. The current was measured by the voltage drop across the resistance $R_{1}(=100 \mathrm{~W})$ connected in series with the discharge system to the ground as in figure 1 . The voltage across the two electrodes was measured using the potential divider of the resistance system $R_{2}, R_{3}$, where $R_{2} / R_{3}=500$.

\section{Preparation of Printing Paste}

The printing paste was prepared according to the following recipe:

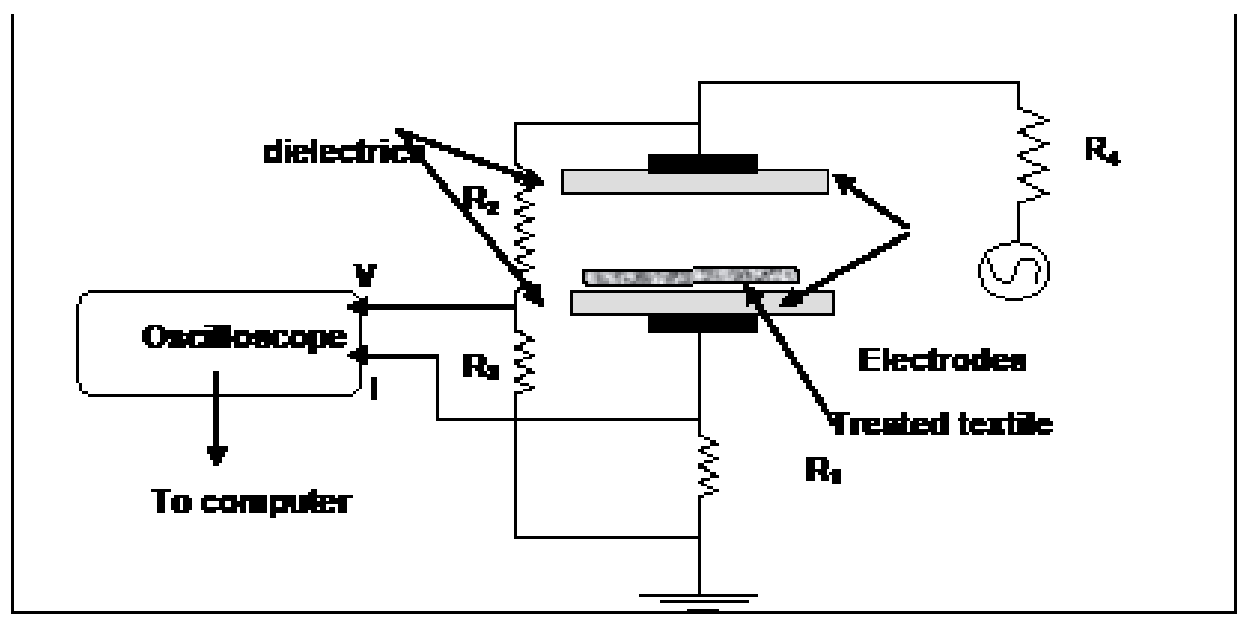

Fig. 1. Schematic diagram of the discharge cell used for the treatment of the textile 


Dye*
Urea
Thickener ${ }^{* *}$
Ammonium sulphate solution $(50 \%)$
Formic acid ( $85 \%)$
Water
*Acid dye used is Supralan Blue $2 \mathrm{R}$ with concentration $4 \%$
**Thickener used is myprogum $5 \%$.

The myprogum is soaked in hot water and well stirred then, the dyestuff is added gradually and complete stirring for few minutes.

\section{Printing Technique}

The samples of the plasma treated and untreated polyamide fabric were printed using conventional silk screen printing technique and air dried. Then, the samples were thermofixed for 2 minutes at $180^{\circ} \mathrm{C}$, and washed according to the following steps:-

- Rinsing with cold water

- Soaping with $1 \mathrm{~g} / 1$ nonionic detergent at $40{ }^{\circ} \mathrm{C}$

- Reduction clear in a solution containing 1-2 g/ 1 sodium hydrosulfate, $1-2 \mathrm{~g} / 1$ caustic soda and $1-2 \mathrm{~g} / 1$ nonionic detergent at a temperature $50^{\circ} \mathrm{C}$.

-Rinsing with water at $50{ }^{\circ} \mathrm{C}$.

-Rinsing with cold water and air dried

\section{Measurements}

\section{Antibacrterial Activity}

Antibacterial activity was carried out by the diffusion disc method. A fabric sample was placed in a Petri dish containing solid bacteria medium (nutrient agar) or fungal medium (Doxs medium), which has been heavily seeded with the spore suspension of the tested organism. The incubation period of the tested microorganism is 24 hours. The tested microorganisms' are Gram positive (Staphylococcus aureue), Gram negative (Escherichia coli), and single cell fungi (Candida albicans). The diameter of the clear zone of inhibition surrounding the sample was taken as a measure of the fabric activity against the particular test organism. An average value of duplicate tests was evaluated ${ }^{(13)}$.

\begin{tabular}{cc}
20 & $\mathrm{~g}$ \\
50 & $\mathrm{~g}$ \\
50 & $\mathrm{~g}$ \\
60 & $\mathrm{~g}$ \\
10 & $\mathrm{~g}$ \\
$\mathrm{X}$ & $\mathrm{g}$ \\
\hline 1000 & $\mathrm{~g}$
\end{tabular}

\section{Wettability}

The wettability was evaluated by measuring the wetting time according to the AATCC-39 method ${ }^{(14)}$. A drop of water is allowed to fall from a fixed height onto the surface of polyamide 6 fabric under examination. The time needed for the drop of water to disappear was measured and had taken as wetting time, and the results were the average value of four readings.

\section{Surface Resistance}

The electrical resistance of samples was determined using a Fluke 8846-6.5 digit precision millimeter. Samples were all tested 10 times in the same direction, and then average values were obtained. The principle involved is a measurement of the voltage drop (product $I R$ ) where:

$(R)$ is the resistance and (I) is the current leaking through the sample.

Surface resistivity was calculated from measured values of surface resistance using the formula, Resistivity in ohms =

Measured resistance in ohms X Width of the specimen.

Distance between the electrodes

\section{Atomic Force Microscopy (AFM)}

Surface morphology of the treated and untreated samples was studies by using a wetSPM9600 Scanning Probe Microscope (Shimadzu Made in Japan). It uses a probe that has a nanosize tip mounted on a flexible cantilever. The tip is scanned slowly across the surface of a specimen. The force between the atoms on the surface of the scanned material and those on the scanning cause the tip to deflect. This deflection can be recorded by using a laser focused on the top of the cantilever 
and reflected onto photo detectors down to the nanoscales. Atomic force microscopy provides high resolution images of surface even if they are nonconducting. In this study, scanning is carried out in contact mode, scanning range is set at a size of $5.0 \mu \mathrm{m} \times 5.0 \mu \mathrm{m}$ and scanning frequency is 1.5 Hz. All images are obtained at ambient conditions immediately after plasma treatment.

\section{Transimsion Electron Microscopy (TEM)}

The effect of glow discharge plasma on the polyamide fabric coating with nano-silver particles and composition of nano silver that performed on the polyamide fabrics was measured by using JEOL electron microscope JET 1230, JOEL LTd, Tokyo, Japan.

\section{$X$-Ray Fluorescence (XRF)}

The amount of silver in the studied fabrics was determined by X-Ray Fluorescence Spectrometer (XRF) - An SEA-2001 (Seikosha Co., Ltd., Tokyo, Japan) was used as the XRF system. For qualitative analysis, the sample area for measurement was directly placed on the collimator of this system, and measurement was performed under the following condition: measurement time, $300 \mathrm{sec}$; diameter of collimator, $10 \mathrm{~mm}$; tube voltage, $50 \mathrm{kV}$; tube current, 2-10 $\mu \mathrm{A}$; sample chamber atmosphere, air; measured element Ag.

\section{Color Assessment (K/S)}

The color yield $(\mathrm{K} / \mathrm{S})$ of each printed sample was measured using a Data Color SF 600plus Colorimeter using a measured area with diameter of $9 \mathrm{~mm}$. All the $(\mathrm{K} / \mathrm{S})$ values were calculated by subtracting the $(\mathrm{K} / \mathrm{S})$ value of the printed untreated sample from the $(\mathrm{K} / \mathrm{S})$ values of the printed treated samples. (i.e values obtained are relative color strength).

\section{Stiffness}

Changes in roughness values were measured for the printed untreated and treated polyamide 6 samples using a surface roughness measuring instrument SEM1700 $\alpha$. The results obtained were the average values of three readings.

\section{Results and Discussion}

IV Characteristics and Power Measurements

Voltage and current wave forms.

Figures $2(a)-(d)$ represent the voltage and current oscillograms for air discharge under atmospheric pressure and at different applied voltages where the currents are a) $0.2 \mathrm{~mA}$, b) $0.6 \mathrm{~mA}, \mathrm{c}) 1 \mathrm{~mA}$, and d) $1.5 \mathrm{~mA}$ respectively.
It is well known that a large number of shortterm micro discharges distinguish the most common attendance of dielectric barrier discharges (DBD) at essential pressure. Each micro discharge has an almost tubular plasma channel, normally of about $100 \mu \mathrm{m}$ radius, and spreads into a larger surface discharge at the dielectric surface $(s)^{(16)}$. The period of the microfilament is of about tens of nanoseconds ${ }^{(17)}$. However, in our present case a homogeneous discharge can be seen to be formed in which the current variation is slower and of longer duration ( $\sim 5 \mathrm{~ms})$, as shown in figure 2 . This discharge is called atmospheric pressure glow discharge (APGD). This discharge is characterized by a homogeneous discharge, which spreads in the discharge gap between the two electrodes. Also it can be noticed that the current pulse and the applied voltage are nearly in phase.

Obtaining the APGD by using porous alumina sheets has been found due to the special formation of the alumina sheets, which are described by the presence of micro holes. An internal discharge takes place inside the microholes and on the surface of the porous alumina. This internal discharge provides seed electrons sufficient for the initiation and growth of the discharge in the APGD form inside gas between the two alumina sheets as it was stated in ${ }^{(18)}$.

\section{The consumed power in the APGD}

The mean power consumed in the APGD can be estimated by taking the incorporation above one rotation of the product of the $I(t)$ and $V(t)$ waveforms ${ }^{(19)}$ where,

$$
p=1 / d S T \int_{0}^{T} I \operatorname{disch}(t) V_{a}(t) d
$$

$\mathrm{P}$ is the power per unit of the discharge volume, $\mathrm{V}_{\mathrm{a}}$ is the applied voltage, $\mathrm{I}_{\text {disch }}$ is the discharge current, $\mathrm{S}$ is the electrode surface, $\mathrm{d}$ is the gas gap, and $\mathrm{T}$ is period.

The mean powers per $\mathrm{cm} 3$ consumed in the APGD have been designed at different currents and have been plotted against these currents as shown in Figure 4. Now, it can be easily calculated the mean power density that consumed in the APGD at different currents from the same Figure 4.

\section{Antibacterial Activity}

The relation between sliver nano particles deposited on the polyamide 6 fabrics and its antibacterial activity - at different discharge 


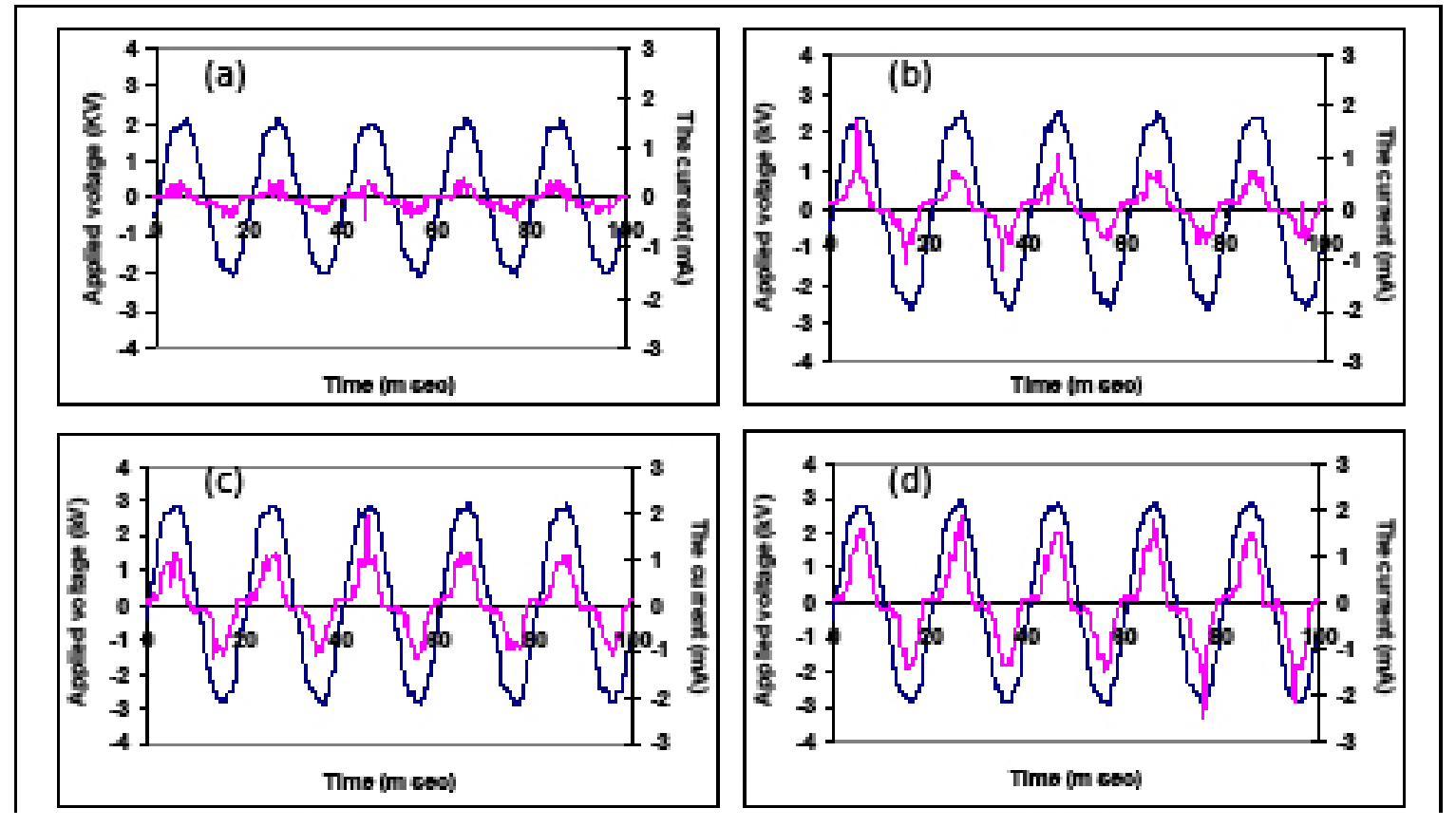

Fig. 2. Current voltage waveforms, where the currents are a) $0.2 \mathrm{~mA}$, b) $0.6 \mathrm{~mA}$, c) $1 \mathrm{~mA}$, and d) $1.5 \mathrm{~mA}$ respectively.

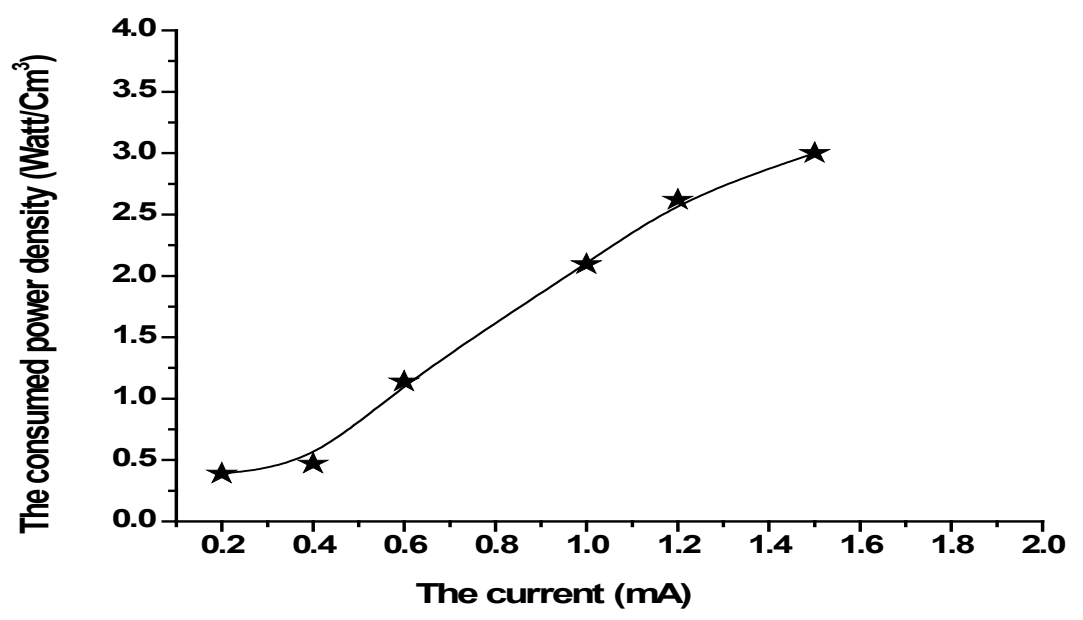

Fig. 3. The consumed power density in the APGD at different currents.

power - were investigated. Figure 4-7 represent the effect of sliver nano particles NPs deposited on the fabric at different plasma exposure times on the antibacterial activity (in terms of clear zone disk) of the treated polyamide 6 fabrics. The results obtained illustrate the effect of the washing cycles - before and after printing - on the treated and untreated polyamide 6 fabrics.

It is discuss that, the antibacterial activity of sliver nano particles NPs (in terms of clear zone kldisk) deposited on polyamide 6 fabrics is slightly increased with increasing conditions of treatment (time and discharge power). The ideal plasma exposure time is 5 minutes; where the highest antibacterial activity could be obtain at discharge power 1.2 and 2 watts $/ \mathrm{cm}^{3}$. This trend holds true at all washing cycles for the treated fabrics.

Concerning the washing processes it is noticed that the show zone distance of the antibacterial activity for the untreated fabric is decreased J. Text. Color. Polym. Sci. ,15, No. 1 (2018) 
gradually. The results obtained are 9, 7 and $0 \mathrm{~mm}$ at washing cycles 5, 10 and 20 . The treated samples for 5 minutes the results obtained are 18, 16, 14 and $18,17,16$ for washing cycles 5,10 , and 20 at discharge power 1.2 and 2 watts $/ \mathrm{cm}^{3}$ respectively. On comparing the results of the antibacterial activity of the plasma treated fabrics before and after printing, very high results could be observed. For example at exposure time 5 minutes, the clear zone distances are 18, 16, 14 for treated polyamide fabric samples versus $21,20,15 \mathrm{~mm}$ for treated printed once. These results are obtained at 5, 10, and 20 of washing cycles respectively.

These higher results in the antibacterial activity obtained after printing may be referred to the presence of the printing paste layer that covers the sliver nano particles deposited on the surface of the treated polyamide 6 fabrics and acts as a barrier and delay the Ag NPs to leave the fabric surface through washing processes.

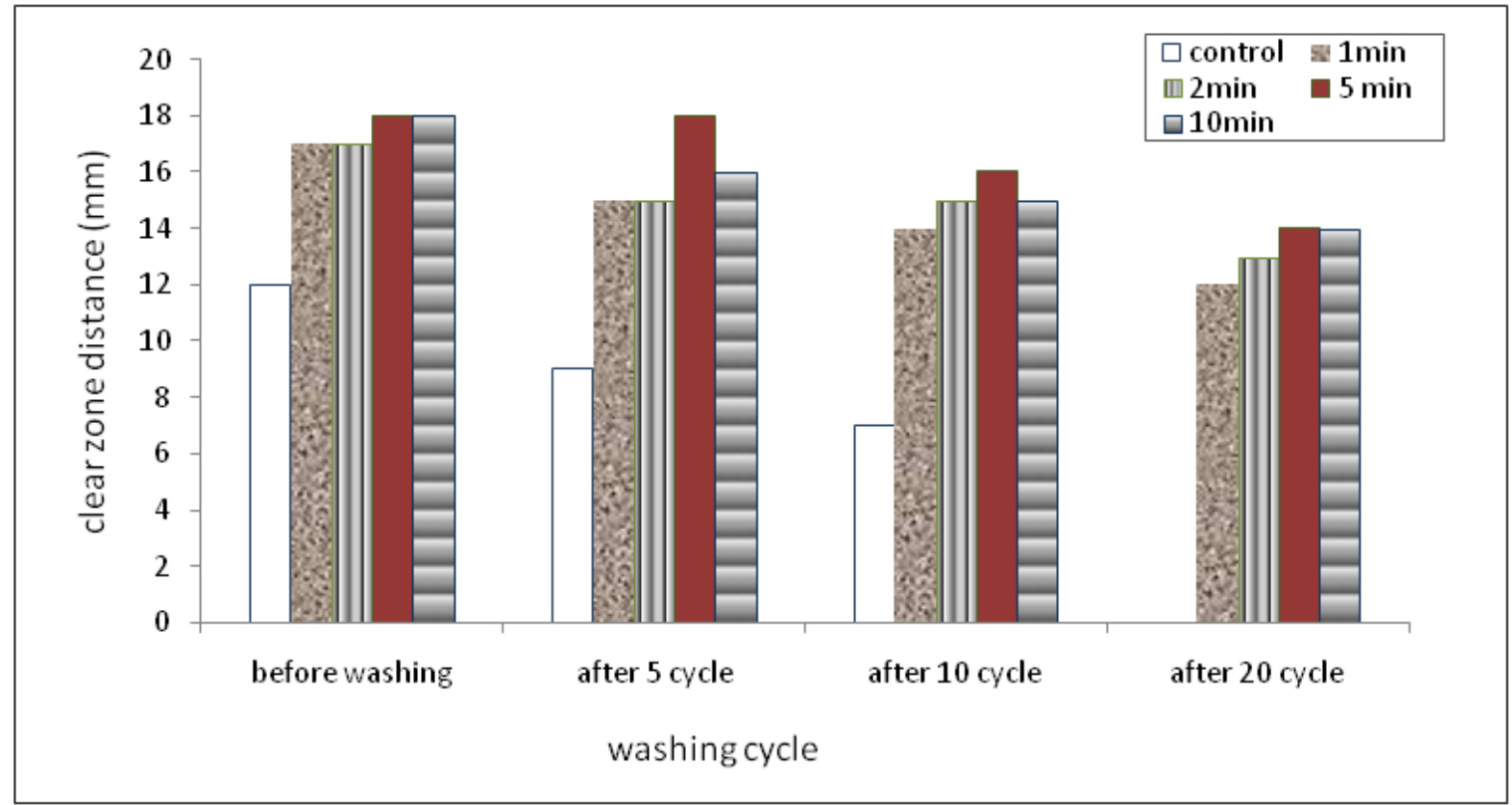

Fig. 4. Effect of the washing process on the antibacterial values of samples treated with glow discharge plasma at 1.2 watts/cm3 for different exposure time.

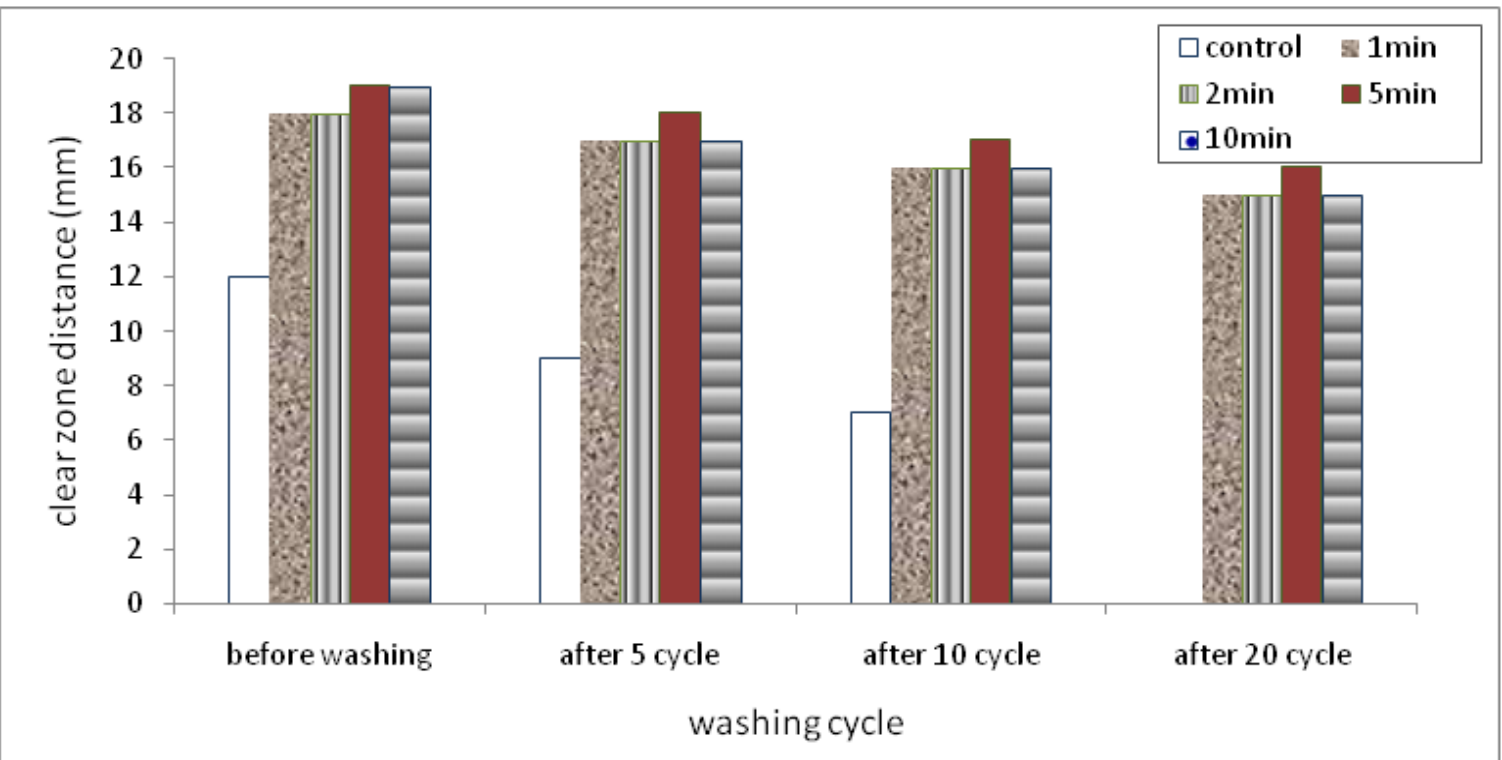

Fig. 5. Effect of the washing process on the antibacterial values of samples treated with glow discharge plasma at 2 watts/cm 3 for different exposure time.

J. Text. Color. Polym. Sci. ,15, No. 1 (2018) 


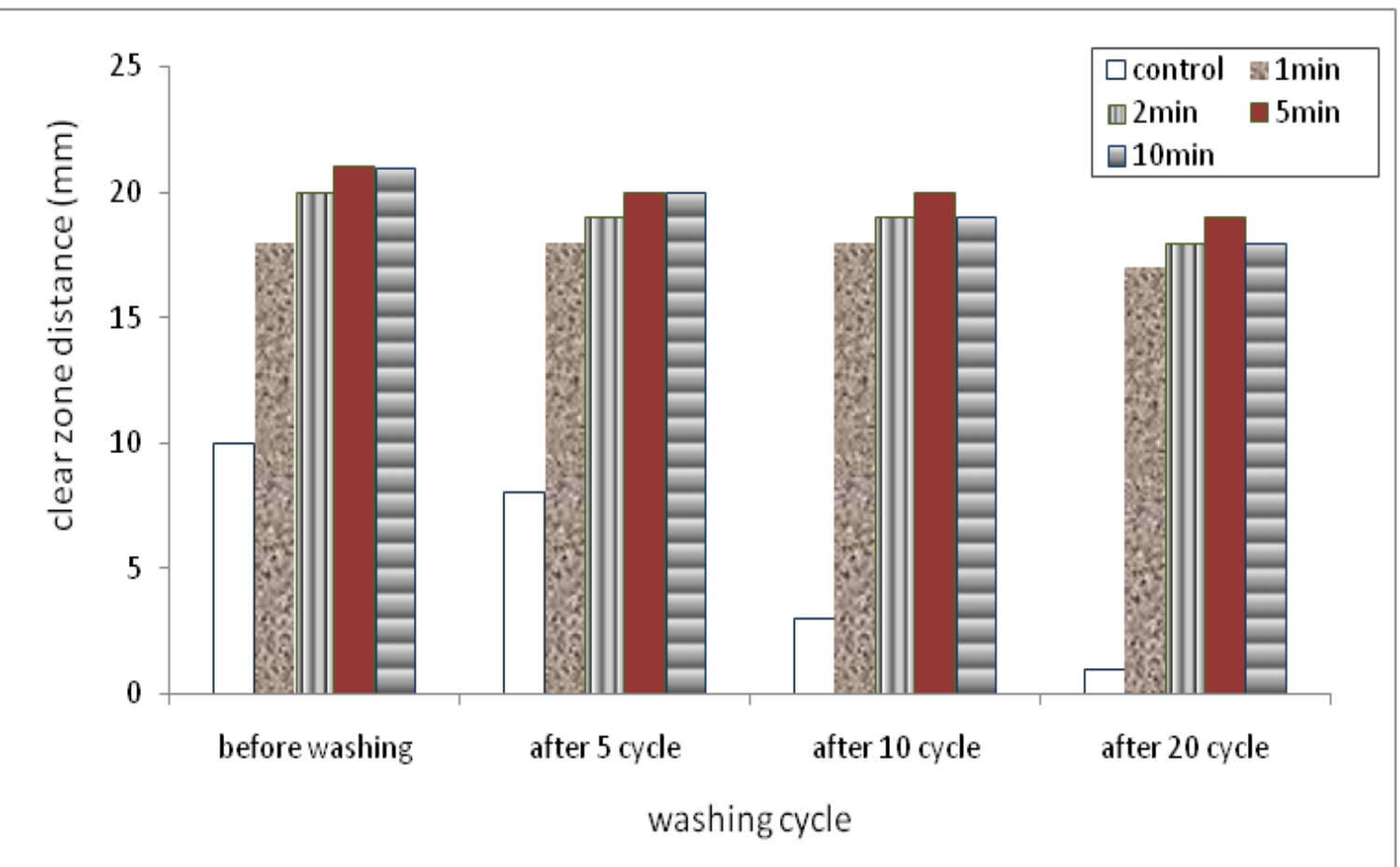

Fig. 6. Effect of the washing process on the antibacterial values of printed samples treated with glow discharge plasma at 1.2 watts $/ \mathrm{cm} 3$ for different exposure time.

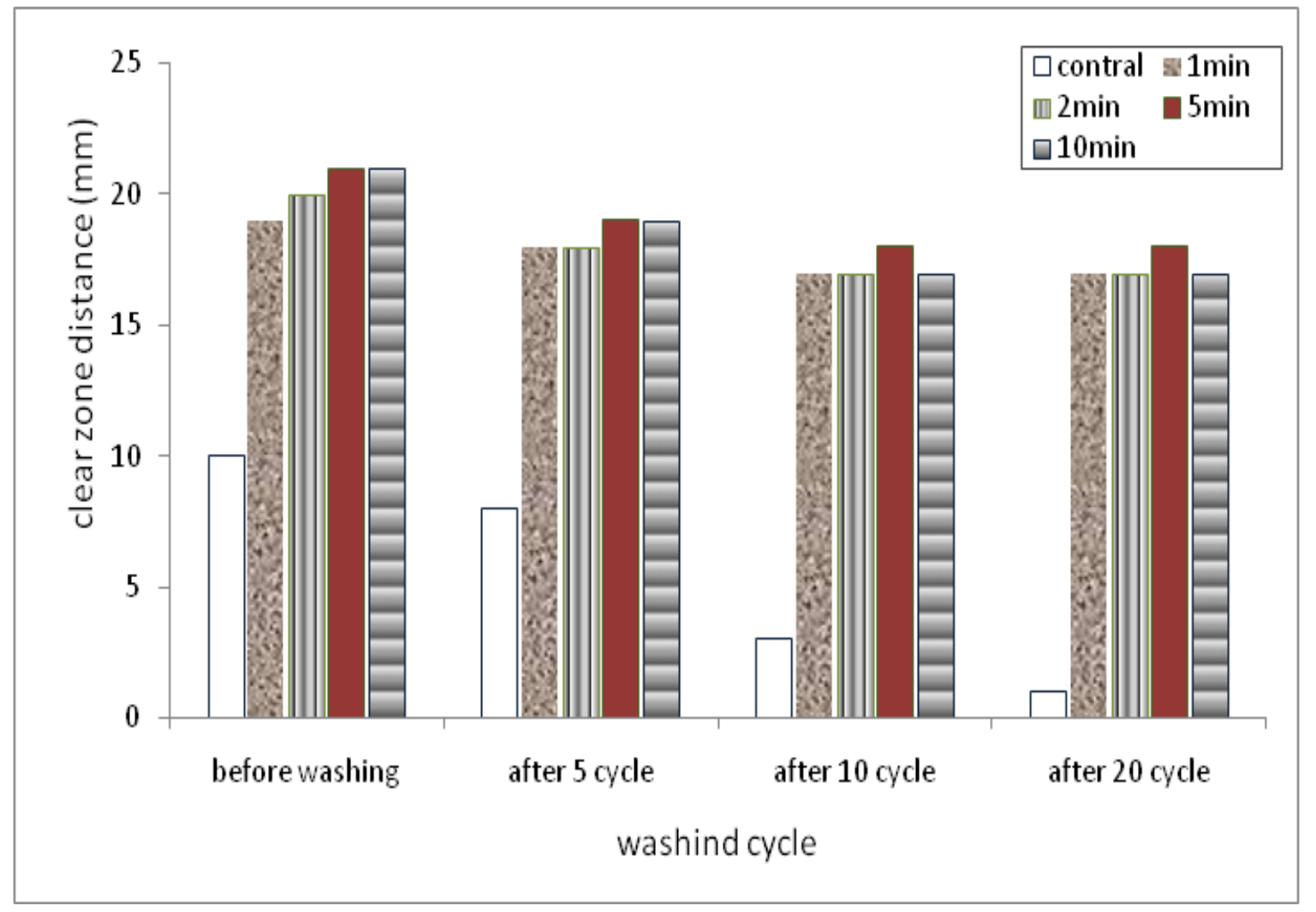

Fig. 7. Effect of the washing process on the antibacterial values of printed samples treated with glow discharge plasma at 2 watts/cm 3 for different exposure time. 
wettability

The wetting time of untreated and treated polyamide 6 fabrics for different exposure times at discharge powers 1.2 and 2 watts $/ \mathrm{cm}^{3}$ are estimated and represented by Figure 8 . The decrease in the wetting time for a drop of water to be disappeared into the fabric means the higher wettability property.

It is observed that the wetting time depends - to a large extent - on the plasma exposure time where, as the exposure time increases the wetting time decreases. The highest wettability achieved at the beginning of the plasma treatment where 1 minute of exposure time gives lower wetting time (6.32 seconds) compared to the time of untreated fabric (17.34 seconds). More than 1 minute of exposure time and up to 5 minutes the wetting time is nearly constant or slightly decreased to reach to 4.47 and 3.9 seconds for treatment time 5 minutes at discharge power levels 1.2 and 2 watts/ $\mathrm{cm}^{3}$ respectively. The increase of the wettability of treated polyamide fabrics may due to the surface etching consequence, a microscopic roughness to the fabric that, increases its surface region ${ }^{(20)}$. Moreover, the molecules on the treatment surface may be also become more active, and some functional groups such as carboxyl, carbonyl groups and hydroxyl radicals may be introduce onto the treatment fabric surface and improve its hydrophilic properties ${ }^{(21)}$.

\section{Surface Resistance}

The resistivity of both untreated and plasma treated polyamide 6 fabrics for different exposure times at discharge power levels 1.2 and 2 watts/ $\mathrm{cm}^{3}$ are represented by Figure 9 .

It is clearly observed that, at each power level, as the time of plasma treatment increases the surface resistivity of polyamide 6 fabric decreases. Also, as the power of the plasma treatment increases, the surface resistivity of polyamide at any given time decreases. Increased discharge power tends to increase surface oxidation, resulting in a lowering of resistivity. For example, at exposure times 1,2 and 5 minutes, the surface resistivity values are 3.8, 3.4 versus 3.1 and 3.0, 1.8 and 1.4 ohms at discharge powers 1.2 and 2 watts $/ \mathrm{cm}^{3}$ respectively. As shown that, surface resistivity values - in all cases - are lower than that of the untreated polyamide 6 fabric $6.88 \mathrm{ohms}$.

These changes in surface resistivity are primarily due to the formation of polar groups on the surface of the fibers, as well as physical changes in the morphology of the polyamide caused by the voids and cracks developing on the fibers which in turn will influence electrical conductivity ${ }^{(15,22)}$.

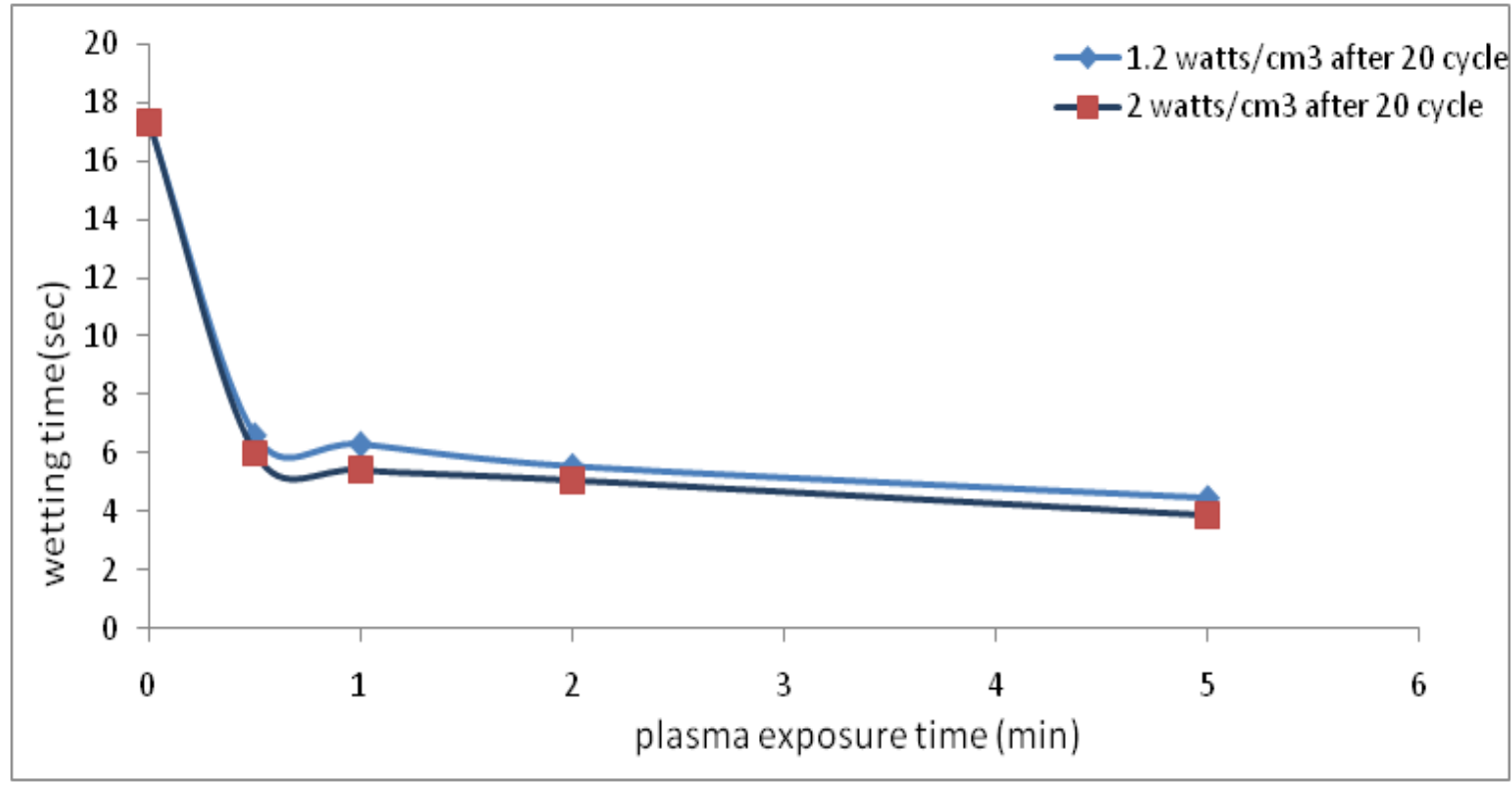

Fig. 8. The wetting time values of samples treated with glow discharge plasma at $1.2 \& 2 \mathrm{watts} / \mathrm{cm} 3$ for different exposure time. 


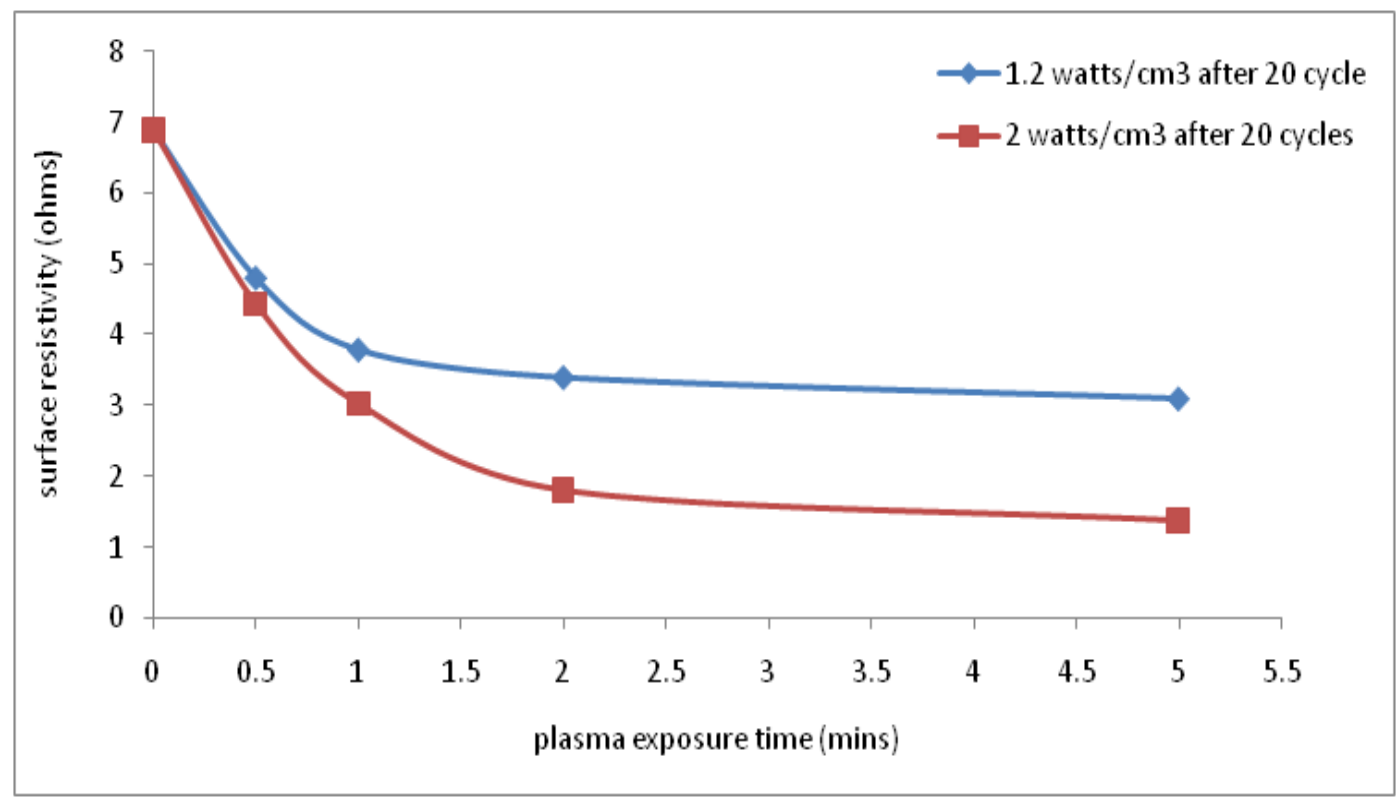

Fig. 9. the surface resistivity values of samples treated with glow discharge plasma at $1.2 \& 2$ watts/cm 3 for different exposure time.

\section{Color Assessment}

Polyamide 6 contains equal numbers of negatively charged carboxylic acid and positively charged amine end-groups. Therefore either anionic or cationic dyes can be used to dye the material ${ }^{(23)}$. Acid dyes, which are anionic in nature, are the most important group for the coloration of polyamide. The dye is initially adsorbed onto the fiber surface, then slowly diffuses into the fiber and forms an ionic bond with the amine end-groups. Since polyamide 6 has only a small number of amine end-groups, it is easily saturated with acid dyes with the result of poor uniformity ${ }^{(24)}$. Figure 10 and 11 appearances different the treatment time and the color strength for the untreated and treated polyamide fabrics at discharge powers 1.2 and 2 watts $/ \mathrm{cm}^{3}$ respectively.

It could be seen that both exposure time and discharge power affected, the color intensity of the treatment fabric. The highest color strength $\mathrm{k} / \mathrm{s}$ value is obtained at 1.2 watts $/ \mathrm{cm}^{3}$ for 5 minutes is 16 versus value 12 for the untreated sample. After washing for 20 cycles, the color strength of the same treated sample decreased from 16 to 12 , while the untreated sample decreased from 12 to 6.8 .

The increase in the color strength $\mathrm{k} / \mathrm{s}$ of the treated polyamide 6 fabric may be due to the increase in activation of the treatment area and its improved on modification due to the introduction of hydrophilic groups on surface as well deposition of sliver on the treated fabric surface shows the role of a mordant which act as a bridge that connect the dye to the polyamide 6 fabric.

\section{Stiffness}

The roughness of the polyamide 6 fabrics with plasma / sliver nano particles Ag-NPs at discharge power 1.2 and 2 watts $/ \mathrm{cm}^{3}$ for different time $(0.5$ 5 minutes) is measured. Table I clears the results obtained.

It is clear that surface roughness is found to be discharge power and exposure time dependent, where increase in both of them are accompanied by a decrease in surface roughness. For example, the treating polyamide 6 for exposure time 5 minutes at discharge powers 1.2 and 2 watts $/ \mathrm{cm}^{3}$ caused a roughness values decrease 14.66 and $13.94 \mathrm{~m} \mu$ respectively compared to $20.5 \mathrm{~m} \mu$ for the untreated fabric. This phenomenon may be due to the presence of the printing paste which filled all the groves and voids that created due to the plasma etching which in turn makes the treated polyamide surfaces become more softener.

\section{Atomic Force Microscope (AFM)}

The surface morphology of the polyamide 6 fabrics is represented in Figure 12. The untreated fabric surface image is represented by Figure 12 (a) while Figure 12 (b) represents the treated polyamide 6 sample for 5 minutes exposure time at discharge power 1.2 watts $/ \mathrm{cm}^{3}$ and washed 20 cycles. 
TABLE I. Stiffness of printed polyamide fabrics - after 20 washing cycles - treated with glow discharge plasma under atmospheric pressure .

\begin{tabular}{|c|c|c|c|c|}
\hline \multirow{2}{*}{$\begin{array}{c}\text { Discharge power } \\
\text { (watts/cm }\end{array}$} & \multicolumn{4}{|c|}{ The stiffens values of the untreated and plasma treated polyamide fabrics for } \\
different intervals of exposure times minutes ,
\end{tabular}

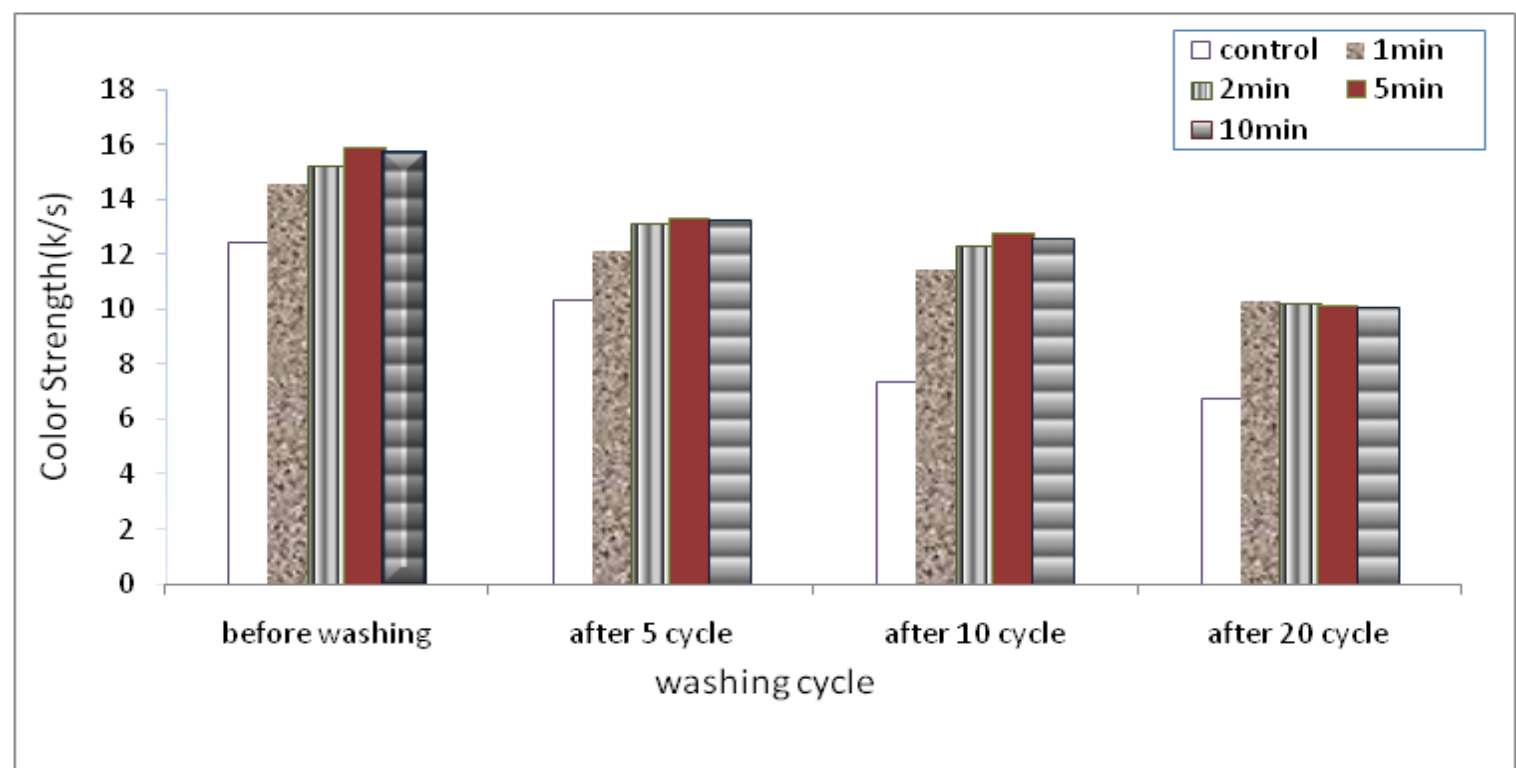

Fig. 10. Effect of the washing process on the color strength values of printed samples treated with glow discharge plasma at 1.2 watts/cm 3 for different exposure time.

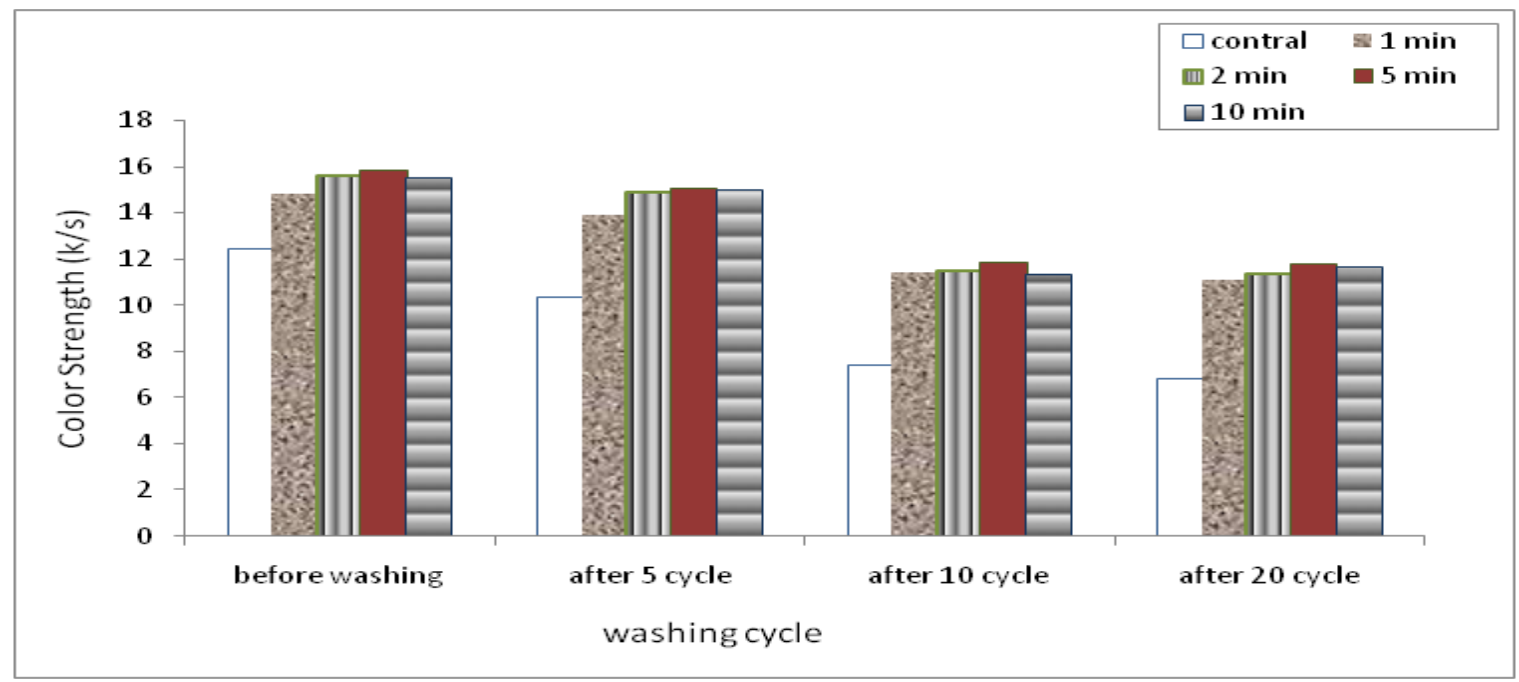

Fig. 11. Effect of the washing process on the color strength values of printed samples treated with glow discharge plasma at 2 watts $/ \mathrm{cm} 3$ for different exposure time.

J. Text. Color. Polym. Sci. ,15, No. 1 (2018) 
AFM investigation noticeably detects the result of the treatment on the surface morphology of the fiber. The AFM appearance (Figure 12a) the relatively smooth surface of the original polyamide 6 fabric. It can be show from Figure 12 (b) that, the fiber structure are noticeably roughed after plasma treatment and silver nano particles deposition. The plasma activation forms collective structures on the fiber surface. The collective creates by etching influence of the plasma bombardment ${ }^{(25)}$. It can also see that the image clearly shows the nanostructures of the placed groups of silver nano particles formed on treatment fiber ${ }^{(26)}$. The sizes of the clusters have various sizes and between them, some of voids and groves are created as a result of the etching effect.

\section{$X$-Ray Fluorescence (XRF)}

The quantities of silver, obtained from XRF, in glow plasma treated polyamide 6 fabric after loading of NPs scaled. The results showed by Figure 13 (a) before washing. The remained silver particles on fabric after 5,10 and 20 cycles of washing are also measured and represented by Figure 13 (b, c, d) respectively. The quantity of sliver \% composition on polyamide 6 fabrics before and after washing was illustrated in Table II.

It is noticed that, the \% Composition of silver nano particles were decreased gradually after washing and the results obtained are $0.51,0.3$ and $0.2 \%$ after 5,10 and 20 cycles of washing

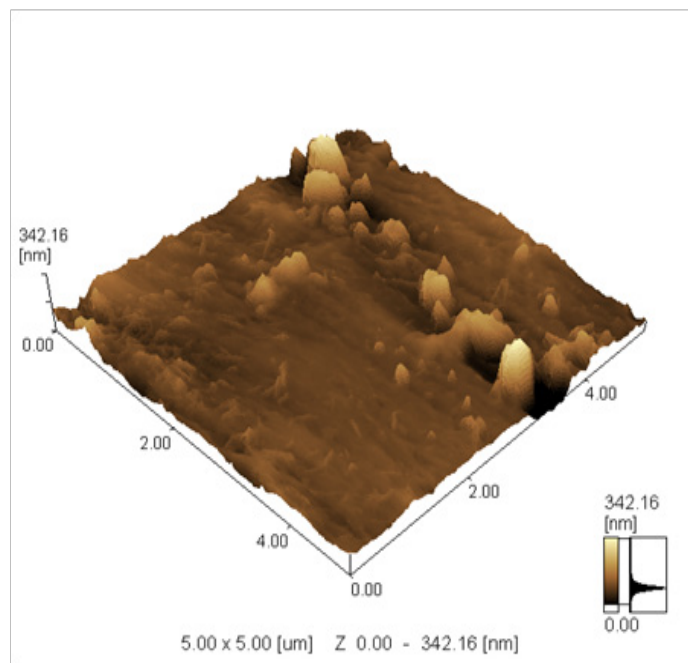

compared to the $\% 0.79$ of Ag NPs sliver before washing. The result designates that nano particles were heavy joined on their substrate and they can have a good bacteriostasis even if only small quantity of nano- silver particles is existing on the fabrics where, nano scaled materials have high ratio of particles number to bulk.

\section{Transimion Electron Microscope (TEM)}

The morphological form of silver nano particles was detected by Transimion Electron Microscope (TEM) in Figure 13 (a \& b). These images are taken for treated polyamide fabric at discharge power 1.2 watts $/ \mathrm{cm}^{3}$ for exposure time 5 min and washed for 10 and 20 cycles respectively.

Figure 14 (a) indications, the TEM chart of plasma / Ag treated polyamide 6 after washing for 10 cycles. The size of the Ag NPs varied between $49-77 \mathrm{~nm}$. While, after 20 washing cycles- as in figure 14 (b) - the size of Ag NPs varies between 29-34 nm. This means that the size of Ag-NPs in both cases - is fewer than $100 \mathrm{~nm}$. It could be also announcement that Ag-NPs dipped perfectly on the fiber surface as shown in Figure 13 (b). The gaps between the NPs on the fibers in both graphs was detected to be unequal. This heterogeneous of Ag-NPs deposition on the fabric surface may be due to the etching carried out through plasma treatment as well as the non-homogeneity of the Ag-NPs distribution on the polyamide 6 surface.

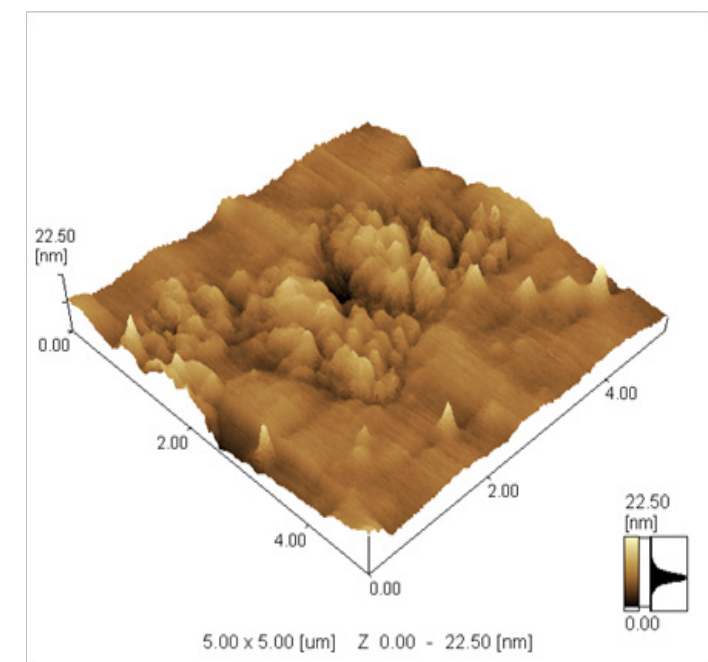

Fig. 12. Evolution of surface morphology observed by AFM: (a) original polyamide 6 fabrics, (b) silver nano particles deposited - after 20 cycle washing - on polyamide treated with glow plasma for 5 minutes at 1.2 watts/cm3. 


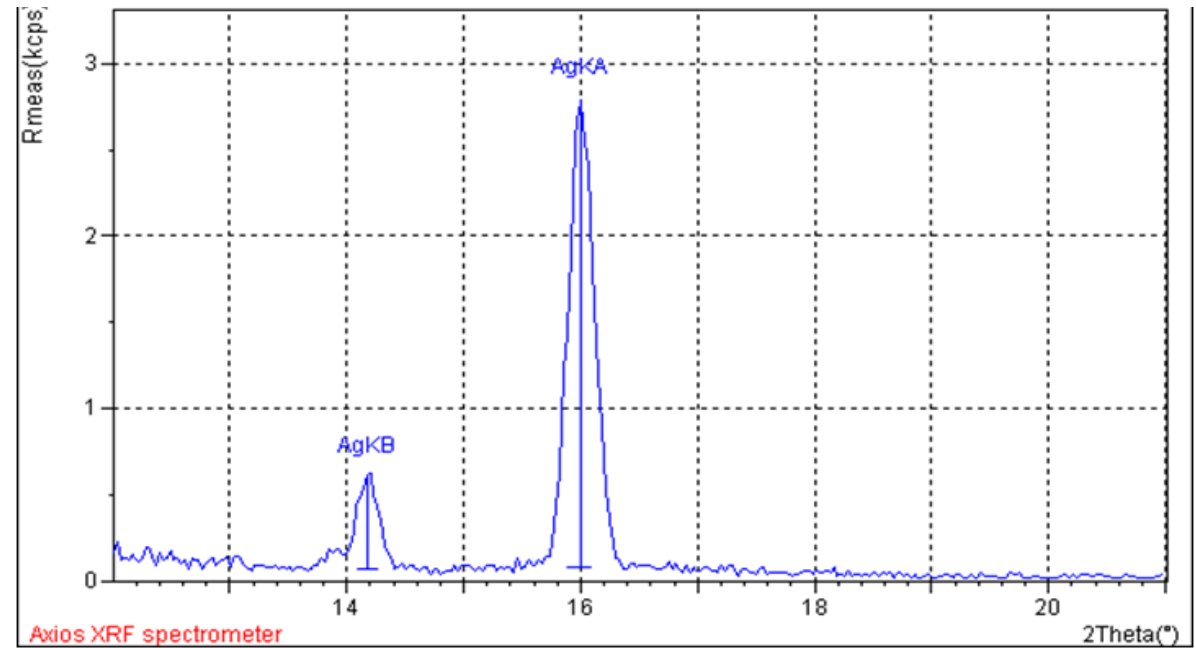

Fig.13 (a). X-ray Fluorescence clearly the amount of Ag NPs deposited - before washing - on polyamide treated with glow discharge plasma for 1.2 watts/cm 3 at 5 minutes exposure time.

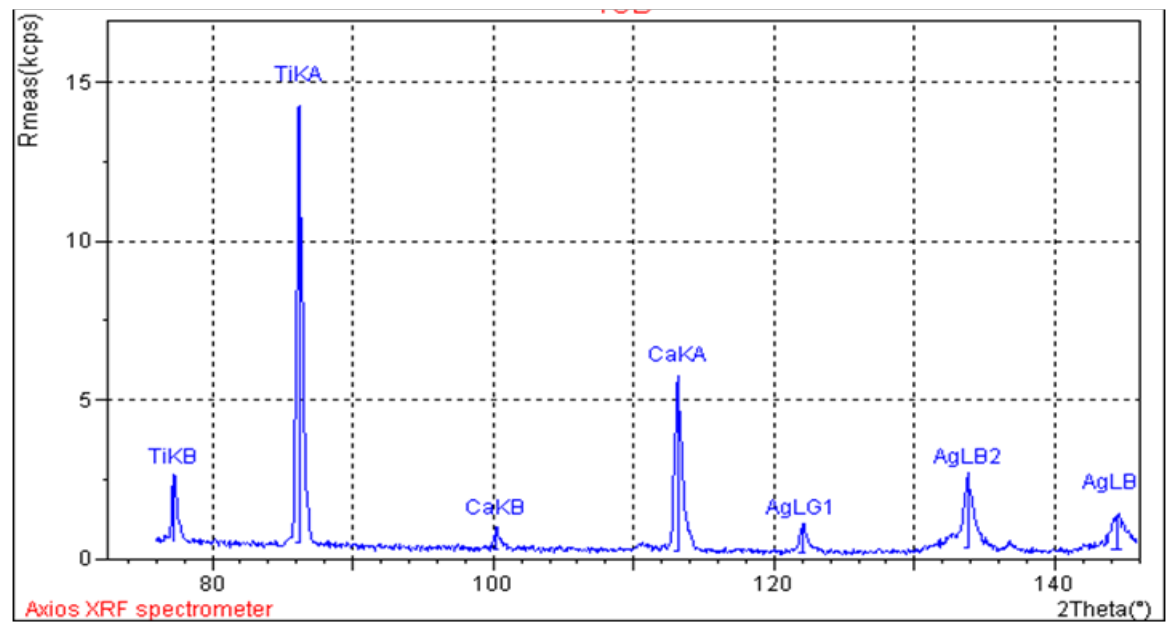

Fig.13 (a). X-ray Fluorescence clearly the amount of Ag NPs deposited - before washing - on polyamide treated with glow discharge plasma for 1.2 watts/cm3 at 5 minutes exposure time.

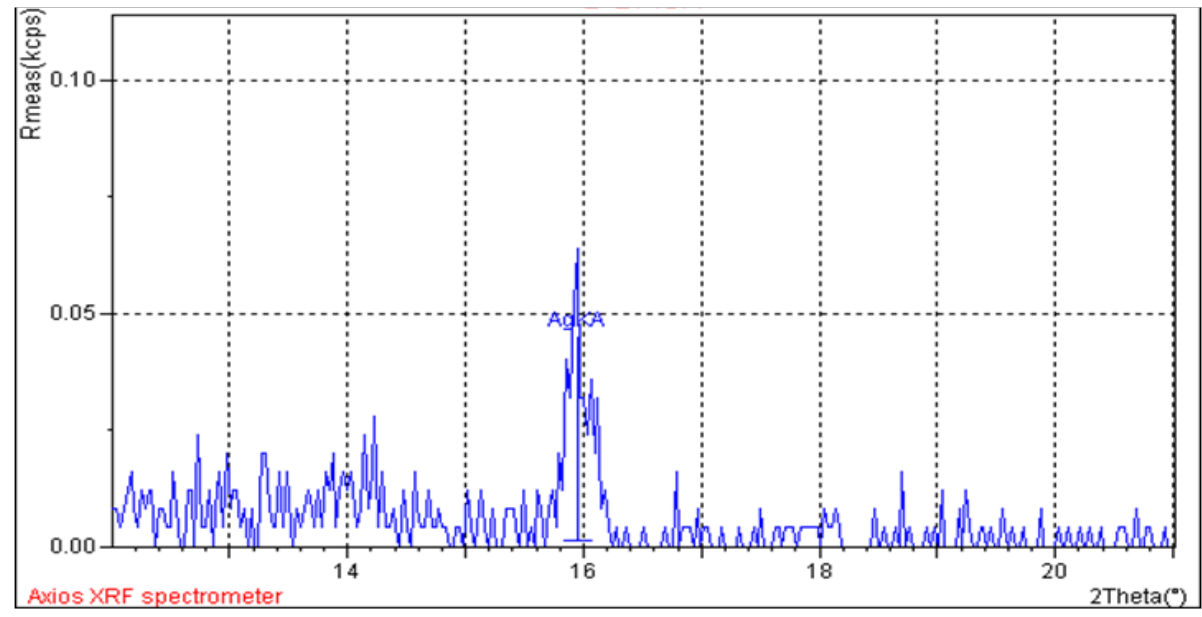

Fig. 13 (b). X-ray Fluorescence clearly the amount of Ag NPs deposited - after 5 cycles washing - on polyamide treated with glow discharge plasma for 1.2 watts $/ \mathrm{cm} 3$ at 5 minutes exposure time.

J. Text. Color. Polym. Sci. ,15, No. 1 (2018) 


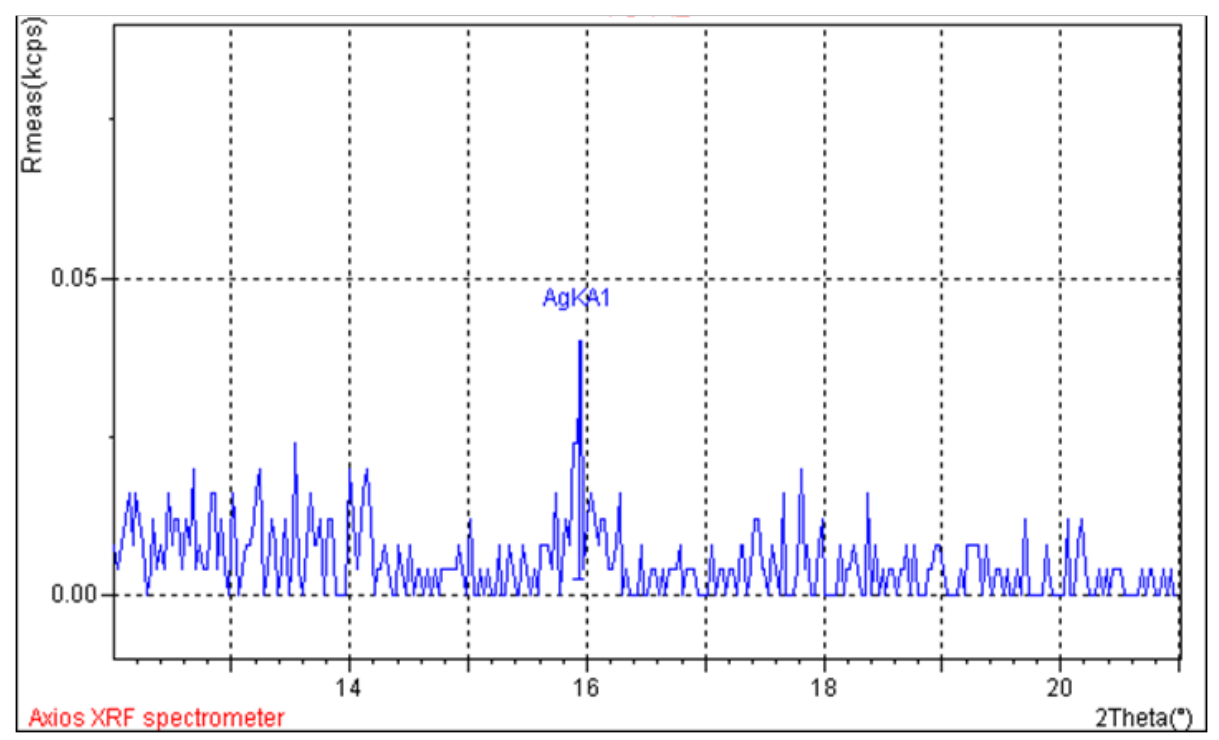

Fig. 13 (c). X-ray Fluorescence clearly the amount of Ag NPs deposited - after 10 cycles washing - on polyamide treated with glow discharge plasma for 1.2 watts/cm 3 at 5 minutes exposure time.

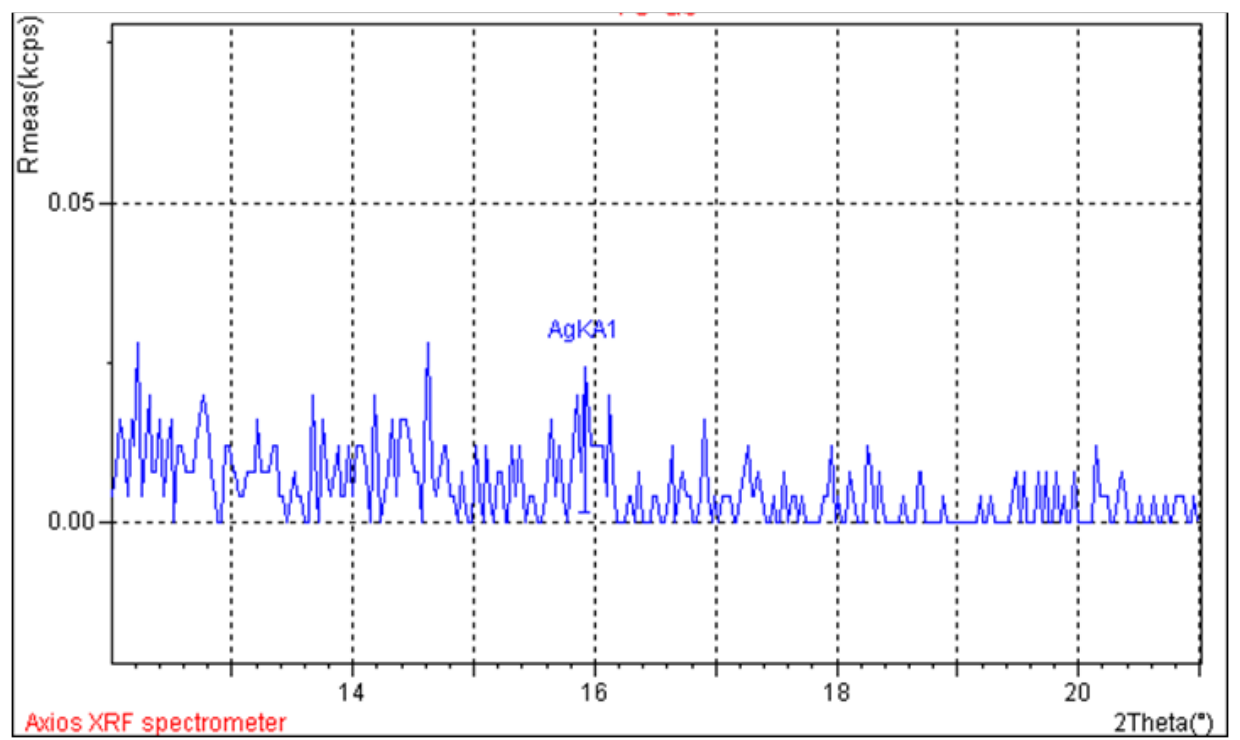

Fig. 13 (d). X-ray Fluorescence clearly the amount of Ag NPs deposited - after 20 cycles washing - on polyamide treated with glow discharge plasma for 1.2 watts $/ \mathrm{cm} 3$ at 5 minutes exposure time. 


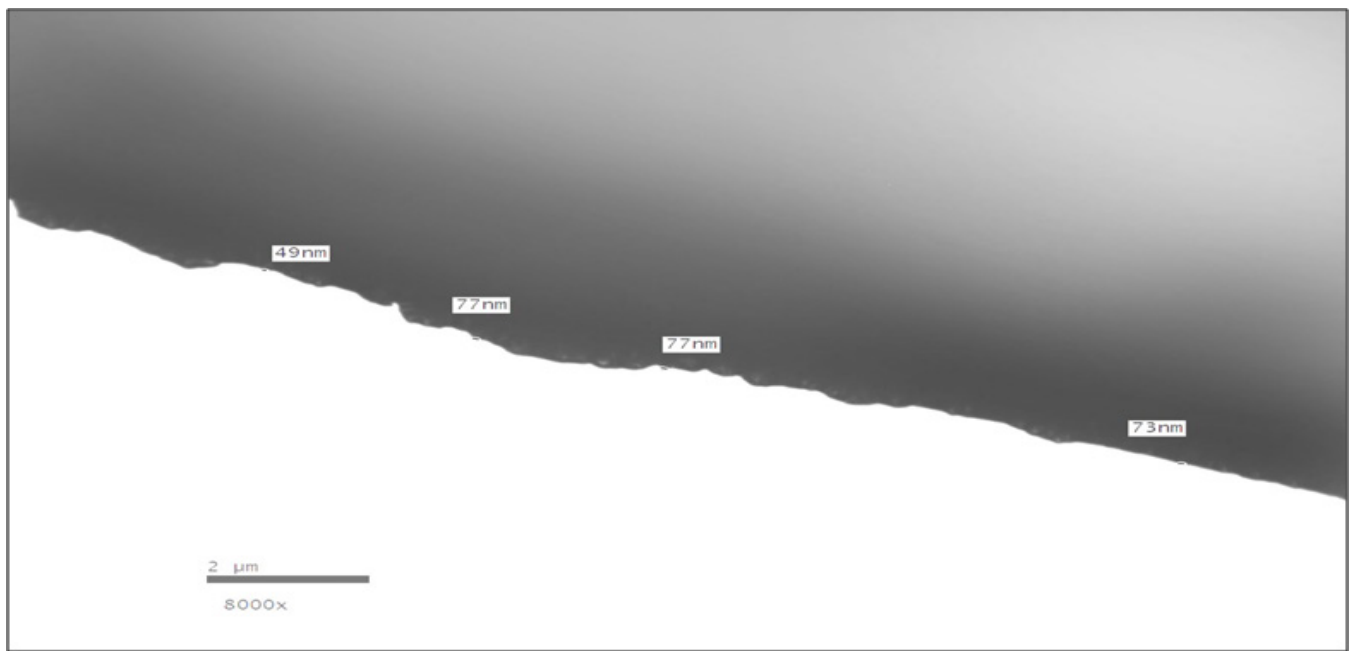

Fig. 14 (a). TEM picture of slivernano particles deposited - after 10 cycles washing - on polyamide treated with GP for $5 \mathrm{~min}$ at1.2 watts $/ \mathrm{cm} 3$.

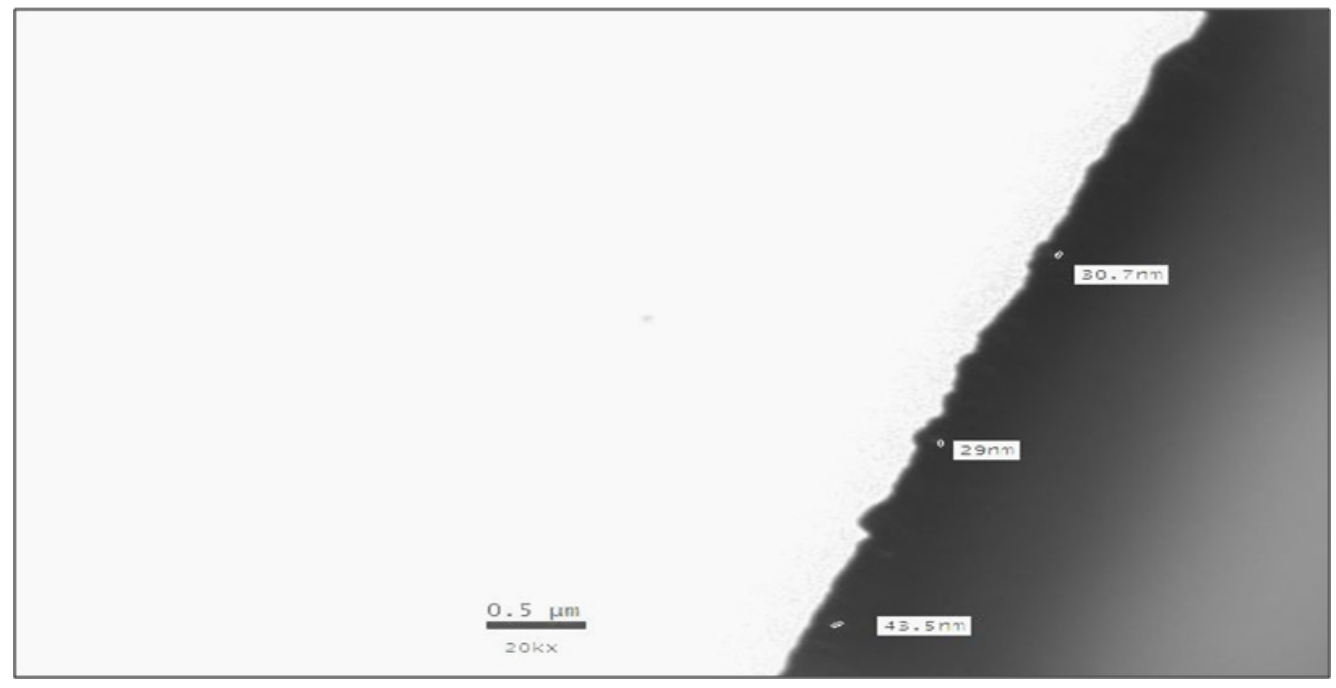

Fig. 14 (b). TEM picture of sliver nano particles deposited - after 20 cycles washing - on polyamide treated with GP for $5 \mathrm{~min}$ at $1.2 \mathrm{watts} / \mathrm{cm} 3$.

\section{References:}

1. H. J. LEE, S. Y. YEO, S. H. JEONG, J. of Materials Science, 38, p.2199-2204(2003).

2. G. Greene, G. Yao, R. Tannenbaum, Langmuir, 19, p.5869 (2003).

3. M. M. Cord, Y. Hwang, Y. Qiu, Y. Hughes, M. Bourham, J. Appl. Polym. Sci., 88, p.2038 (2003).

4. T. Wakida, M. Lee, Y. Sato, S. Ogasawara, Y. Ge, S. Niu, J. Soc. Dyers Color, 112, p.233 (1996).

5. J. Ryu, T. Wakida, T. Takagishi, Text. Res. J., 61, p.595 (1991).

J. Text. Color. Polym. Sci. ,15, No. 1 (2018)
6. S.M. Mukhopadhyay, P. Joshi, S. Datta, J. Macdaniel, Appl. Surf. Sci., 201, 219(2002).

7. P. Favia, M. Vulpio, R. Marino, R. d'Agostino, R. P. Mota, M. Catalano, Plasmas Polym., 5,1-14 (2000).

8. Vincent J L, Bihari D J, Suter P M, Bruining H A, White J, Nicolas-Chanoin M H, Wolff M, Spencer R C, Hemmer M, 'Journal of the American Medical Association, 274, p.639-644 (1995).

9. D. J. Balazs, K. Triandafillu, P. Wood, Y. Chevolot, D. C. Van, H. Harms, C. Hollenstein, H. J. Mathieu, Biomaterial, 25, p.2139-2151(2004). 
10. P. Favia, R. d'Agostino, Surf. Coat. Technol., 98, p.1102-1106 (1998).

11. R. L. Davies, S. F. Etris, Catalysis Today, 36, p.107-114 (1997).

12. C. L. Fox, B. W. Rappole, W. Stanford, Gynecology and Obstetrics, 128, p.1021 (1969).

13. M. Tsukada, T. Arai, G.M. Colonna, A. Boschi \& G. Freddi, J. of Applied Polymer Science, 89, p. 638 (2003).

14. AATCC, Technical Manual, Test Method, 39, (1971).

15. N.V. Bhat, Y.N. Benjamin, Textile Res. J., 69, p.3842 (1999).

16. U. Kogelschatz, Plasma Chem. Plasma Processing., 23, p. 1-46 (2003).

17. V. Alexandr, V. Chirokov, "Stability of Atmospheric Pressure Glow Discharges", A Thesis Submitted to the Faculty of Drexel University, (2005).

18. A.A. Garamoon, and D.M. El-zeer, Plasma Sources Sci. Tech., 18 , p.194-201(2009).

19. N. Gherardi, G. Gouda, E. Gat, A. Ricard and F.Massines, Plasma Sources Sci. Tech., 9, p. $340-346$ (2000).
20. A. Bendak, W.M. Raslan \& M.Salma, J. of Natural Fibers, 5, p.251(2008).

21. Q.F. Wei, W.D. Gao, D.Y. Hou, , X.Q. Wang, Appl. Surf. Sci., 245, p.16-20(2005).

22. A.M. Wrobel, M. Kryszewski, W. Rakoroski, M. Odoniewske, \& Z. Kubacki, Polymer, 19, p.908-912 (1978).

23. P. Ginns, K. Silkstone \& D.M. Nunn, "The Dying of Synthetic Polymer and Acetate Fibers", Bradford: SDC, p.243 (1979).

24. Y. Joanne, C. Kwong, M.S. Kwan,\& L. Kai, Color. Technol., 118, p.26-30(2002).

25. W. Qufu, W. Yingying, W. Xueqian , H. Fenglin, Y. Shengwei, J. of Appl. Poly. Sci., 106, p.12431247(2007).

26. D. Tao, Q. Wei, Y. Cai, Q. Xu, J. Coat. Technol. Res., 5(3), p.399-403(2008).

(Received 10/10/2018; accepted 22/11/2018)

\section{التأثير المضاد للجراثيم باستخدام الجسيمات النانوية الفضية المحملة على نسيج البولي

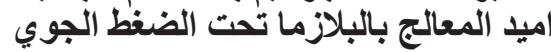

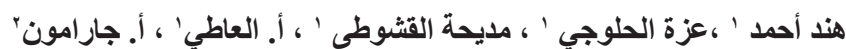

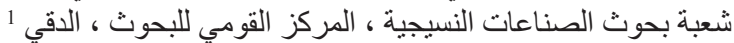

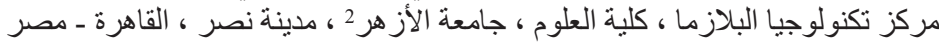

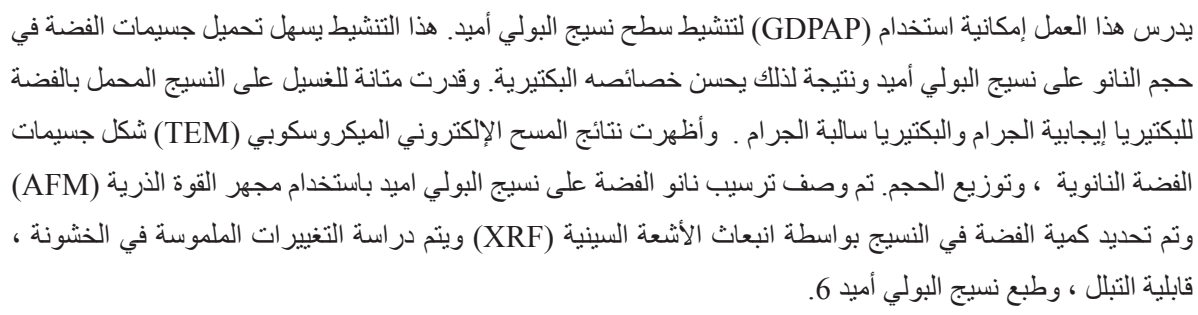

